Bangladesh J. Bot. 49(3): 601-609, 2020 (September)

\title{
ULTRASONICATION ASSISTED EXTRACTION OF TOTAL FLAVONOIDS FROM KAEMPFERIA GALANGA L. AND ITS ANTIOXIDANT ACTIVITY
}

\author{
Zhaobao Xiang ${ }^{1 *}$, XiaOling Wu ${ }^{2}$ and Xue Zhong ${ }^{1}$ \\ Key Laboratory of Natural Medicine Research of Chongqing Education Commission, \\ Chongqing Technology and Business University, Chongqing-400067, China
}

Keywords: Total flavonoids, Ultrasonication assisted extraction, Kaempferia galanga, Response surface methodology, Antioxidant activity

\begin{abstract}
Ultrasonication assisted extraction (UAE) was employed to extract total flavonoids (TF) from Kaempferia galanga L. (KGL) roots. Single-factor experiments were performed to evaluate the effects of the process parameters (solvent-to-material ratio, ethanol concentration, extraction time, ultrasonic power, and extraction temperature) on the TF yield and the response surface methodology (RSM) was used to optimize the extraction parameters. The optimum conditions to obtain the maximum TF yield were solvent-to-material ratio, 25; ethanol concentration, $62 \%$; extraction time, $27.0 \mathrm{~min}$; extraction temperature, $50^{\circ} \mathrm{C}$ and ultrasonic power, $225 \mathrm{~W}$. The yield of TF under these conditions reached $3.22 \pm 0.12 \mathrm{mg} / \mathrm{g}$ of dry root. The analysis of variance and validation test indicated that the proposed method is useful and reliable. The antioxidant capacities of TF of KGL was determined by DPPH. and $\mathrm{ABTS}^{+}$. methods, which revealed that it has good antioxidant activity in both systems.
\end{abstract}

\section{Introduction}

Kaempferia galanga L. is indigenous to tropical Asia, where it is commonly used in traditional medicine for the management of swelling, rheumatism, cough, dysentery, diarrhea, and stomachache (Ridtitid et al. 2008). Meanwhile, the roots of KGL are commonly used as flavoring agent in foods and spices because its taste is spicy and aromatic. In spite of these valuable properties, comparatively little is known about KGL and it is unutilized (Li et al. 2017). Recently, flavonoids have received increasing attention because they exhibit many kinds of biological activities, such as antitumor (Shao et al. 2005), antivirus (Evers et al. 2005), anti-oxidation (Han et al. 2009), antidiabetic (Li et al. 2014) and strengthening the immune system (Deng et al. 2011). There are some flavonoids in KGL, such as kaempferol and kaempferide. However, little is known about the extraction of total flavonoids from KGL and its process optimization.

Many effective methods for the extraction of flavonoids from plant sources have been employed intensively, such as ultrasonic-assisted extraction (UAE) (Yang et al. 2010), microwave-assisted extraction (MAE) (Zhang et al. 2012), ultrasonic-microwave assisted extraction (UMAE) (Xiang and Wu 2017), supercritical fluid extraction (SFE) (Wang et al. 2008), and ultrahigh pressure extraction (UPE) (Sun et al. 2015). Among these, UAE has proved to be a particularly effective extraction method to reduce the extraction temperature and amount of solvent and shorten the extraction time, which is especially useful for the extraction of thermosensitive and unstable compounds. The mechanism of UAE is attributed to mechanical and cavitation effects that can result in disruption of cell wall, particle size reduction, and enhanced

\footnotetext{
*Author for correspondence: <xiangzb@126.com>. ${ }^{1}$ College of Environment and Resources, Chongqing Technology and Business University, Chongqing, 400067 China. ${ }^{2}$ Academic Quality Inspection and Evaluation Office, Chongqing Technology and Business University, Chongqing, 400067 China.
} 
mass transfer across cell membranes (Ju et al. 2015). There are a few reports on using UAE to extract total flavonoids (TF) from KGL, but it is important to establish general rules about variables that affect TF extraction, as it is significantly influenced by operating conditions. Hence, it is still necessary to establish the optimum extraction conditions to obtain high yield of TF from KGL by means of UAE.

Response surface methodology (RSM) is an important tool for the optimization of process parameters, robust design, and other quality improvement efforts. RSM can map a response surface over a particular region of interest, optimize the response, and select operating conditions to achieve desired specifications. Hence, it has been applied in many chemical and biochemical processes such as TF extraction (Guo et al. 2013, Xiang et al. 2018). As per as knowledge goes there is no reports about the application of RSM to optimization of the TF extraction from KGL. In the present work, RSM was used to optimize the UAE of TF from KGL. Oxidative modification of DNA, proteins, lipid and small cellular molecules by reactive oxygen species (ROS) increases the risk of a wide range of common degenerative diseases such as osteoporosis, cancer and cardio-vascular diseases. Antioxidants are of great importance in terms of reducing ROS so as to lower the incidence rate of degenerative diseases. Increasing dietary intake of natural antioxidants, such as polyphenols and flavonoids, has been shown to have an inverse association with the risks of cardiovascular diseases, inflammatory conditions, neurodegenerative diseases, diabetes mellitus and cancer (Chen et al. 2014). However, there are no reports on antioxidant activity of TF from KGL. Thus, the aim of the present work was to establish the optimized parameters of UAE for the TF extraction from KGL, test the antioxidant activity of TF from KGL and offer scientific reference for development and utilization of the resource.

\section{Materials and Methods}

The roots of KGL were purchased from Taiesen Pharmaceutical Co. Ltd., Chongqing, China in October 2017. The material was passed through a 60-mesh screen with a grinder to obtain a homogeneous powder, and then stored at $4{ }^{\circ} \mathrm{C}$. Rutin was purchased from Push Bio-technology Co. Ltd., Chengdu, China. All other chemicals and reagents used were of analytical grade. The absorbance was measured on a U-2910 spectrophotometer from Hitachi Hi-Tech company, Takyo, Japan. The UAE was carried out on a Scientz-IID Ultrasonic extraction apparatus from Xinzhi Biological Instruments Co. Ltd., Ningbo, China.

Only $2.00 \mathrm{~g}$ was extracted with a digital timer and a temperature controller. Weighed amount $(2.00 \mathrm{~g})$ of plant powder was placed into a capped round bottom flask fitted with water condenser pipe and treated for different times at various powers. After UAE, the sample was centrifuged at $4000 \mathrm{rpm}$ for $10 \mathrm{mins}$ to collect the supernatant. The extract was evaporated by rotary evaporation at $50^{\circ} \mathrm{C}$ to remove excess ethanol, and then the solution was transferred to a $25 \mathrm{ml}$ flask and diluted to the mark with $30 \%$ ethanol.

TF content was determined using the aluminum colorimetric method (Xiang et al. 2017). Briefly, $1.00 \mathrm{ml}$ TF extract was mixed with $11.50 \mathrm{ml} 30 \%$ aqueous ethanol, and $0.60 \mathrm{ml} 5 \%$ $\mathrm{NaNO}_{2}$, shaken, and allowed to stand for 5 mins. Then, $0.60 \mathrm{ml} 10 \% \mathrm{Al}\left(\mathrm{NO}_{3}\right)_{3}$ was added to the mixture and it was allowed to stand for 5 mins again. Finally, $5.00 \mathrm{ml} 4 \% \mathrm{NaOH}$ was added to the mixture. After incubation at room temperature for $15 \mathrm{mins}$, the absorbance of the resulting reaction mixture was measured at $500 \mathrm{~nm}$ with a spectrophotometer. The volume of $10 \%$ $\mathrm{Al}\left(\mathrm{NO}_{3}\right)_{3}$ was substituted by the same amount of distilled water in blank. Rutin was used as a standard. Using a six-point calibration curve $(0-128 \mathrm{mg} / \mathrm{ml})$, the TF yield was defined as (milligram rutin quivalent/gram dry plant powder). 
The antioxidant activity was evaluated by using the 2,2-diphenyl- $\beta$-picryl hydrazyl radical (DPPH), just as described in the literature (Mottaghipisheh et al. 2015). The DPPH radical solution was dissolved in $95 \%$ ethanol with a final concentration of $0.10 \mathrm{mmol} / \mathrm{l}$, the absorbance of the mixture solution with $2.70 \mathrm{ml}$ DPPH radical solution and $0.30 \mathrm{ml}$ ethanol was measured as the negative control. the TF solution in ethanol $(0.30 \mathrm{ml})$ with different concentrations was pipetted into $2.70 \mathrm{ml} \mathrm{DPPH}$. radical solution. Then after a 30 min incubation period at room temperature in the dark, the absorbance was read against the blank at $517 \mathrm{~nm}$. The $\mathrm{DPPH} \cdot$ scavenging activity was expressed according to the following equation:

$$
\mathrm{S} \%=\left(\mathrm{A}_{\mathrm{c}(0)}-\mathrm{A}_{\mathrm{A}(\mathrm{t})}\right) / \mathrm{A}_{\mathrm{c}(0)} \times 100 \%
$$

where, $\mathrm{A}_{\mathrm{c}(0)}$ is the absorbance of the negative control reaction, and $\mathrm{A}_{\mathrm{A}(\mathrm{t})}$ is the absorbance 0.30 $\mathrm{ml}$ sample and $2.70 \mathrm{ml}$ DPPH. solution at $517 \mathrm{~nm}$. All samples were analyzed in triplicate. $\mathrm{DPPH}$. scavenging activity of the sample was expressed as $50 \%$ scavenging concentration $\left(\mathrm{SC}_{50}\right)$, which represented the sample concentration $(\mathrm{mg} / \mathrm{ml})$ scavenging $50 \%$ of the DPPH. radical activity. Here Vc was the positive control group.

The $\mathrm{ABTS}^{+}$scavenging activity was measured as described ( $\mathrm{Li}$ et al. 2012) with some modification. Firstly, the $\mathrm{ABTS}^{+}$working fluid was produced by mixing $0.20 \mathrm{ml} \mathrm{ABTS}^{+}$solution $(7.4 \mathrm{mmol} / \mathrm{l})$ with $0.20 \mathrm{ml}$ potassium persulfate $(2.60 \mathrm{mmol} / \mathrm{l})$. The mixture was kept in the dark at room temperature for $12 \mathrm{hrs}$, then diluted about 50 times with $95 \%$ ethanol after sufficient reaction, To determine the scavenging activity, $8.00 \mathrm{ml}$ aliquot of $\mathrm{ABTS}^{+}$. reagent was mixed with $2.00 \mathrm{ml}$ sample solution in different concentration, standing for 6 mins in the dark after shaking for $10 \mathrm{sec}$ immediately, the absorbance at $734 \mathrm{~nm}$ was read against the blank, The $\mathrm{ABTS}^{+} \cdot$ scavenging activity of samples was calculated as:

$$
\mathrm{I} \%=\left(\mathrm{A}_{0}-\mathrm{A}\right) / \mathrm{A}_{0} \times 100 \%
$$

where, $\mathrm{A}_{0}$ is the absorbance at $734 \mathrm{~nm}$ containing $8.00 \mathrm{ml} \mathrm{ABTS}{ }^{+}$. working solution and 2.00 $\mathrm{ml} 95 \%$ ethanol, while A is the absorbance at $734 \mathrm{~nm}$ with $8.00 \mathrm{ml} \mathrm{ABTS}^{+}$. working solution and $2.00 \mathrm{ml}$ samples. All samples were analyzed in triplicate, the $\mathrm{ABTS}^{+}$. scavenging activity of the test sample was also expressed as $\mathrm{SC}_{50}$ using $\mathrm{Vc}$ as positive control group.

\section{Results and Discussion}

In the preliminary study, variables affecting TF extraction were ethanol concentration (\%), solvent-to-material ratio $(\mathrm{ml} / \mathrm{g})$, extraction time $(\mathrm{min})$, ultrasonic power $(\mathrm{W})$ and extraction temperature $\left({ }^{\circ} \mathrm{C}\right)$. Their effects are presented in Fig. 1A. Fig. 1 A shows that the TF yield initially increased and then decreased with increasing ethanol concentration, the maximum $\mathrm{TF}$ yield corresponding to the ethanol concentration of $60 \%$. The reason might be that the yield of alcoholsoluble impurities, plant pigments, and lipophilic ingredients increased with the ethanol concentration. The amounts of these components and TF in the extract competitively varied with ethanol-water molecules combination, resulting in lower yield of TF. In this case, the optimum ethanol concentration for the extraction of $\mathrm{TF}$ was $60 \%$, which is used for Box-Behnken central composite experimental design (Xiang and $\mathrm{Wu} 2017$ ).

Fig. 1B shows that, with increasing solvent-to-material ratio, the TF yield initially increased and then gradually decreased. Generally speaking, the TF yield initially increased with the solvent- to-material ratio, but when the amount of solvent reached a certain value, the TF was almost completely extracted, and TF yield remained stable. In this case, the solvent-to-material ratio of 25 was determined as most appropriate.

According to Fig. 1C, when the ultrasonic power increased, the TF yield exhibited significant initial growth and then remained basically stable. Therefore, the optimum ultrasonic power was $200 \mathrm{~W}$ in view of the cost of product and yield, which is used for Box-Behnken central composite experimental design. 
According to Fig. 1D, when the extraction temperature increased, the TF yield initially increased and then decreased with the maximum TF yield observed for the extraction temperature of $50^{\circ} \mathrm{C}$, probably because over-exposure to high temperature may lead to thermal degradation of $\mathrm{TF}$ constituents. Therefore, the optimum extraction temperature was $50^{\circ} \mathrm{C}$.
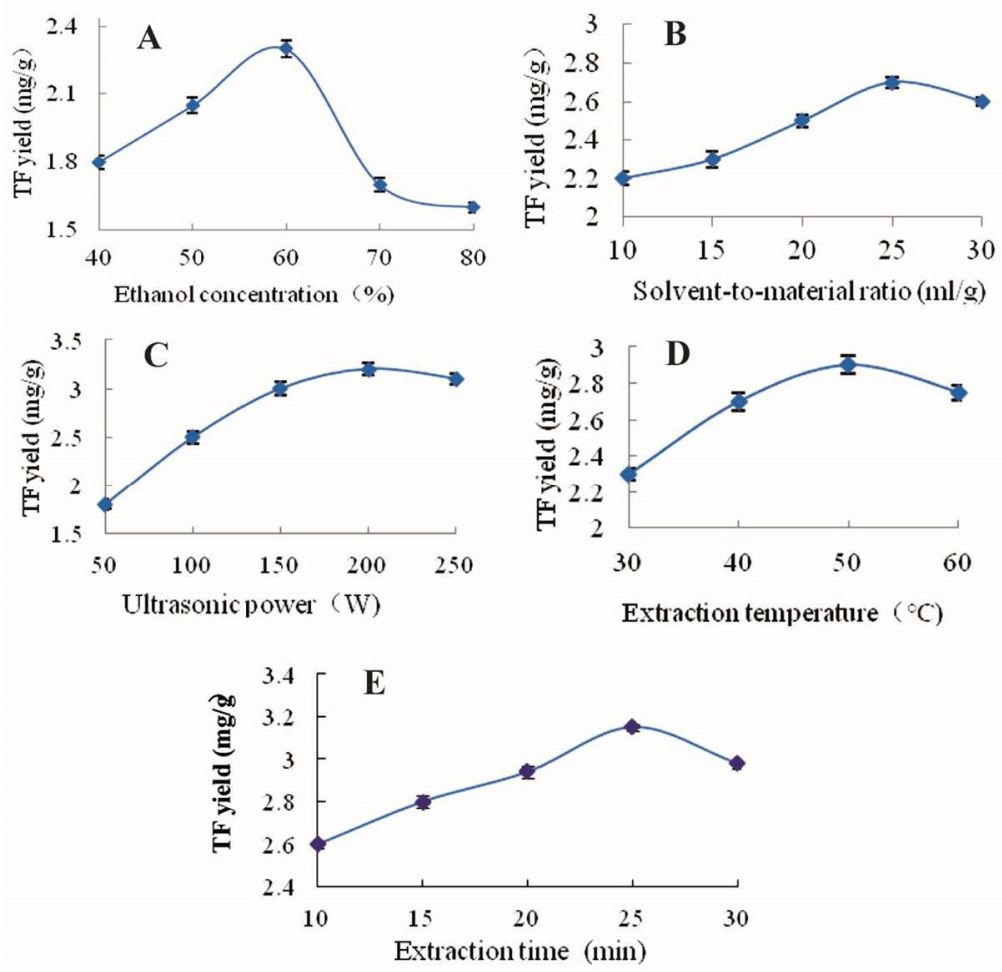

Fig. 1. Single-factor test results. A. Effect of ethanol concentration. B. Effect of solvent-to-material ratio,

C. Effect of ultrasonic power. D. Effect of extraction temperature and E. Effect of extraction time.

The effect of different extraction time on yield of TF is shown in Fig. 1E. It can be seen that, increase in the extraction time significantly increased the yield at the initial stage. But further increase in the ultrasonic time did not show any increase in the TF yield when the extraction time was more than $25 \mathrm{~min}$, probably because over-exposure to ultrasonic wave may lead to thermal degradation of $\mathrm{TF}$ constituents. Accordingly, 25 mins was chosen as the extraction time in succeeding experiments. Therefore, the optimum extraction time was 25 mins, which is used for Box-Behnken central composite experimental design (Xiang and Wu 2017).

According to the results of single-factor tests, Box-Behnken central composite experimental design principles and RSM were used to optimize the process conditions for UAE of TF. The three variables were ultrasonic power, ethanol concentration and extraction time. Table 1 shows the results of experimental data with coded levels for TF in KGL roots.

By applying multiple regression analysis to the experimental data, the response variable $Y$ and the test variables $X 1$-- $X 3$ were related by the following equation:

$$
\begin{aligned}
Y & =3.18+0.014 X 1+0.045 X 2+0.053 X 3-(2.250 \mathrm{E}-003) X 1 X 2+(8.500 \mathrm{E}-003) X 1 X 3+0.034 \\
X 2 X 3 & -0.087 X 1^{2}-0.073 X 2^{2}-0.071 X 3^{2}
\end{aligned}
$$


The corresponding variables would be more significant if the absolute F-value becomes greater and $\mathrm{p}$-value becomes smaller. The values of $F$ and $P(\mathrm{p}<0.05$ when significant) were 9.94 and 0.0031 , respectively, in the adopted model, indicating that the model adequately described data variation and significantly represented the actual relationship between the process parameters. Meanwhile, the coefficient of determination $\left(R^{2}=92.74 \%\right)$ showed that $92.74 \%$ of the observed variations were explained by the model. The model "fitness" was investigated through the lack-offit test ( $p>0.05$ ), which indicated the suitability of models to accurately predict the variation (Guo et al. 2013). These values would give a relatively good fit to the Mathematic model expressed by Eq. (1).

Table 1. Program and experimental results of RSA.

\begin{tabular}{ccccc}
\hline No. & $\begin{array}{c}\text { XI: ethanol } \\
\text { concentration }(\%)\end{array}$ & $\begin{array}{c}\text { X2: extraction } \\
\text { time }(\mathrm{min})\end{array}$ & $\begin{array}{c}\text { X3: ultrasonic } \\
\text { power }(\mathrm{w})\end{array}$ & $\begin{array}{c}\text { Y: TF yield } \\
\mathrm{mg} / \mathrm{g}\end{array}$ \\
\hline 1 & $60(0)$ & $30(+1)$ & $250(+1)$ & $3.13 \pm 0.12$ \\
2 & 60 & $20(-1)$ & $150(-1)$ & $3.01 \pm 0.15$ \\
3 & $50(-1)$ & $25(0)$ & 250 & $3.08 \pm 0.10$ \\
4 & 60 & 30 & 150 & $2.98 \pm 0.09$ \\
5 & $70(+1)$ & 25 & 150 & $2.95 \pm 0.11$ \\
6 & 60 & 25 & $200(0)$ & $3.20 \pm 0.13$ \\
7 & 50 & 25 & 150 & $2.96 \pm 0.12$ \\
8 & 50 & 30 & 200 & $3.07 \pm 0.09$ \\
9 & 70 & 20 & 200 & $2.97 \pm 0.13$ \\
10 & 50 & 20 & 200 & $2.93 \pm 0.12$ \\
11 & 60 & 25 & 200 & $3.20 \pm 0.15$ \\
12 & 70 & 25 & 250 & $3.10 \pm 0.11$ \\
13 & 60 & 25 & 200 & $3.20 \pm 0.09$ \\
14 & 60 & 20 & 250 & $3.03 \pm 0.10$ \\
15 & 60 & 25 & 200 & $3.18 \pm 0.12$ \\
16 & 70 & 30 & 200 & $3.11 \pm 0.15$ \\
17 & 60 & 25 & 200 & $3.14 \pm 0.14$ \\
\hline
\end{tabular}

From Eq. (1) it is apparent that the TF yield from KGL has a complex relationship with independent variables. The best way of expressing the effects of independent variables on the TF yield within the experimental space under investigation is to generate response surface plots of the equation. The three-dimensional (3D) plots can directly reflect the effects of various factors on the response value, and values of each factor under optimum conditions can be seen in the contour. The 3D response surfaces and corresponding contour plots have been obtained using the SAS method and are shown in Fig. 2 to illustrate the relationship between independent variables and the TF yield.

As can be seen from Fig. 2, the ultrasonic power $(X 3)$ has the most significant effect on the UAE of TF from KGL, which can be seen by a steeper curve in the 3D plots, too. The extraction time $(X 2)$ also produced significant effect on the UAE yield, although it is weaker than the effect of ultrasonic power. The ethanol concentration $(X I)$ had less significant effects, which is manifested by smooth 3D plots: as the value increases, the changes in response value are small, which is consistent with results of the analysis of variance. 
Table 2. Analysis of variance for the quadratic polynomial model.

\begin{tabular}{lclllll}
\hline Source & $\begin{array}{c}\text { Degrees of } \\
\text { freedom }\end{array}$ & $\begin{array}{l}\text { Sum of } \\
\text { squares }\end{array}$ & $\begin{array}{l}\text { Mean } \\
\text { square }\end{array}$ & $F$-value & $P$-value & \\
\hline Model & 9 & 0.13 & 0.014 & 9.94 & 0.0031 & Significant \\
$X 1$ & 1 & 0.001485 & 0.001485 & 1.02 & 0.3465 & \\
$X 2$ & 1 & 0.01602 & 0.01602 & 10.99 & 0.0129 & \\
$X 3$ & 1 & 0.02279 & 0.02279 & 15.63 & 0.0055 & \\
$X 1 X 2$ & 1 & $2.025 \mathrm{E}-05$ & $2.025 \mathrm{E}-05$ & 0.01389 & 0.9095 & \\
$X 1 X 3$ & 1 & 0.000289 & 0.000289 & 0.1982 & 0.6696 & \\
$X 2 X 3$ & 1 & 0.004692 & 0.004692 & 3.22 & 0.1159 & \\
$X 1^{2}$ & 1 & 0.03220 & 0.03220 & 22.08 & 0.0022 & \\
$X 2^{2}$ & 1 & 0.02256 & 0.02256 & 15.47 & 0.0057 & \\
$X 3^{2}$ & 1 & 0.02149 & 0.02149 & 14.74 & 0.0064 & \\
Residual & 7 & 0.010201 & 0.001458 & & & \\
Lack of fit & 3 & 0.007250 & 0.002417 & 3.2690 & 0.1412 & Not significant \\
Pure error & 4 & 0.002957 & 0.0007393 & & & \\
\hline
\end{tabular}

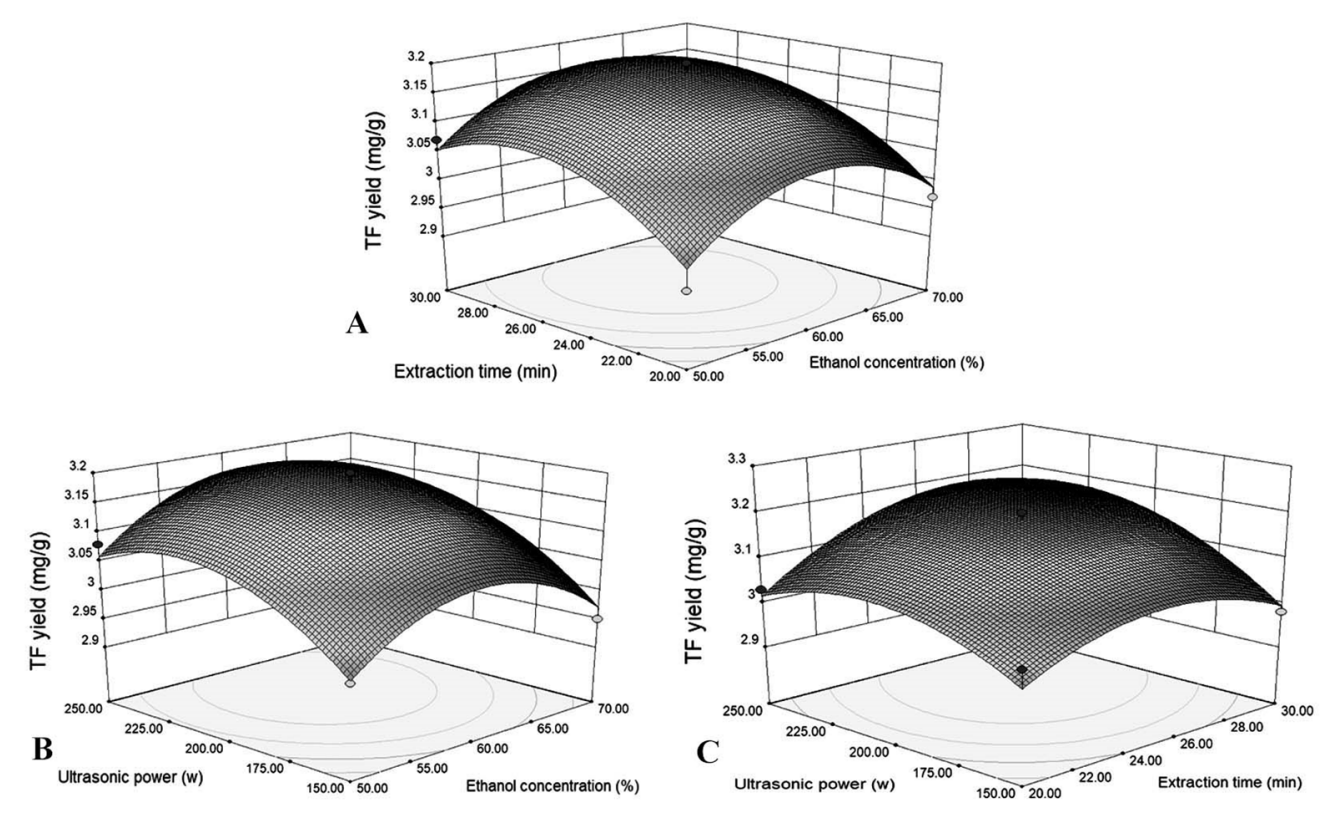

Fig. 2. 3D plots and contour of the combined effects. A. Extraction time and ethanol concentration. B. Ultrasonic power and ethanol concentration and C. Ultrasonic power and extraction time.

The corresponding optimum conditions of the UAE of TF from KGL roots are as follows: ethanol concentration, $62 \%$; extraction time, $25.67 \mathrm{~min}$; and ultrasonic power $225.56 \mathrm{~W}$. Under these conditions, the theoretical TF yield reached $3.20 \mathrm{mg} / \mathrm{g}$ of dry root powder. 
The convenience of actual production operations was also taken into account. The process was repeated three times to extract $\mathrm{TF}$ under the following conditions: solvent-to-material ratio, 25; ethanol concentration, $62 \%$; extraction time, $26.0 \mathrm{~min}$; extraction temperature, $50.0^{\circ} \mathrm{C}$; ultrasonic power, $225 \mathrm{~W}$. The experimental TF yield under these conditions reached $3.22 \pm 0.12$ $\mathrm{mg} / \mathrm{g}$, which is in close agreement with the predicted values. The relative error between experimental and predicted values was $0.63 \%$ (compared to the mean value). Therefore, the UAE conditions of TF from KGL optimized by RSM are feasible and reliable.

Flavonoid is a strong active natural product, and antioxidant is one of the most basic capacity. there are so many methods to evaluate the potential antioxidant activity due to different mechanisms. DPPH. and $\mathrm{ABTS}^{+}$are both especially effective way to test the antioxidant activity. In the DPPH assay, the targeted extract act as donors of hydrogen atoms or electrons in transformation of DPPH. into DPPH--H. It can damage the stability of DPPH. solution, which turn purple-colored radical DPPH. into yellow-colored DPPH--H (Szabo et al. 2007). With Vc as positive control, the radical scavenging activity of TF of KGL was tested by DPPH. assays. For both, in certain range of concentrations, there existed a good linear correlation between antioxidant activities and concentrations. While they arose a high concentration, the antioxidant activities was seen to vary gently. The $\mathrm{SC}_{50}$ value was as follow: $0.0375 \mathrm{mg} / \mathrm{ml}$ for $\mathrm{Vc}, 0.1084$ $\mathrm{mg} / \mathrm{ml}$ for $\mathrm{TF}$ of KGL (Table 3). Based on the $\mathrm{SC}_{50}$ values, it is obvious that the TF of KGL expressed good DPPH radical scavenging activity. In order to evaluate TF of KGL more credibly, $\mathrm{ABTS}^{+}$. system for determination of antioxidant capacity has also been adopted. In the $\mathrm{ABTS}^{+}$. assay, the $\mathrm{SC}_{50}$ values of $\mathrm{Vc}$ and $\mathrm{TF}$ of $\mathrm{KGL}$ were $0.0626 \mathrm{mg} / \mathrm{ml}$ and $0.1273 \mathrm{mg} / \mathrm{ml}$, respectively (Table 4). The result showed that the TF of KGL expressed good $\mathrm{ABTS}^{+}$. radical scavenging activity.

Table 3. DPPH scavenging activities of total flavonoids of KGL.

\begin{tabular}{lcccc}
\hline Sample & $\begin{array}{c}\text { Regression } \\
\text { equation }\end{array}$ & $\begin{array}{c}\mathrm{SC}_{50} \\
(\mathrm{mg} / \mathrm{ml})\end{array}$ & $\begin{array}{c}\text { Linaer range } \\
(\mathrm{mg} / \mathrm{ml})\end{array}$ & $\mathrm{R}^{2}(\%)$ \\
\hline $\mathrm{Vc}$ & $\mathrm{y}=29.35 \ln (\mathrm{x})+106.6$ & 0.0375 & $0.025-0.2$ & 99.24 \\
$\mathrm{TF}$ of KGL & $\mathrm{Y}=8.15 \ln (\mathrm{x})+32.62$ & 0.1084 & $0.125-2.0$ & 99.55 \\
\hline
\end{tabular}

Table 4. ABTS $^{+}$. scavenging activities of total flavonoids of KGL.

\begin{tabular}{lcccc}
\hline Sample & $\begin{array}{c}\text { Regression } \\
\text { equation }\end{array}$ & $\begin{array}{c}\mathrm{SC}_{50} \\
(\mathrm{mg} / \mathrm{ml})\end{array}$ & $\begin{array}{c}\text { Linear range } \\
(\mathrm{mg} / \mathrm{ml})\end{array}$ & $\mathrm{R}^{2}(\%)$ \\
\hline $\mathrm{Vc}$ & $\mathrm{y}=19.82 \ln (\mathrm{x})+98.73$ & 0.0626 & $0.0125 \sim 0.2$ & 99.36 \\
TF of KGL & $\mathrm{y}=16.68 \ln (\mathrm{x})+67.70$ & 0.1273 & $0.125 \sim 2.0$ & 99.59 \\
\hline
\end{tabular}

In this work, an adequate mathematical model of various factors and response was established on the basis of single-factor tests. The UAE yield of TF from KGL has a complex relationship with independent variables. The effects of ethanol concentration, extraction time, and ultrasonic power on the TF yield are not described by simple linear relationships; the influence of these factors on the TF yield can be rated as follows: ultrasonic power > extraction time > ethanol concentration. The former two factors have significant influence, while the latter has not. The UAE conditions of TF from KGL were optimized by RSM. The optimum conditions of UAE of TF are as follows: solvent-to-material ratio, 25; ethanol concentration, 62\%; extraction time, 26.0 
min; extraction temperature, $50.0^{\circ} \mathrm{C}$; ultrasonic power, $225 \mathrm{~W}$. The corresponding TF yield was $3.22 \pm 0.12 \mathrm{mg} / \mathrm{g}$. Validation experiments were carried out to verify the applicability and accuracy of the model, and the results showed that the predicted values were in good agreement with the experimental data. The antioxidant activity of TF of KGL was very good, its $\mathrm{SC}_{50}$ on DPPH and ABTS was about 3 and 2 times that of the positive control $(\mathrm{Vc})$, respectively.

\section{Acknowledgments}

This work was supported by the Key Laboratory of Natural Medicine Research of Chongqing Education Commission, Chongqing Technology and Business University (KFJJ2019094) and Scientific Research Starting Foundation of Chongqing Technology and Business University (2015-56 -07).

\section{References}

Chen ZC, Mei X, Jin YX, Kim EH, Yang ZY and Tu YY 2014. Optimisation of supercritical carbon dioxide extraction of essential oil of flowers of tea (Camellia sinensis L.) plants and its antioxidative activity. J. Sci. Food Agric. 94: 316-321.

Deng W, Zheng MQ, Zhang J, Huang C and Zhang YL 2011. Immunologic functions of total flavone of Epimedium of two species in Guizhou. Chin. J. Chin. Mater. Medi. 36(4): 511-513.

Evers DL, Chao CF, Wang X, Zhang Z and Huong SM 2005. Human cytomegalovirus-inhibitory flavonoids: Antiviral activity and mechanism of action. Antivirus Res. 68(3): 124-134.

Guo L, Zhu WC, Liu YT, Wu JY, Zheng AQ and Liu YL 2013. Response surface optimized extraction of flavonoids from Mimenghua and its antioxidant activities. Food Sci. Biotechnol. 22(5): 1285-1292

Han RM, Tian YX, Liu Y, Chen CH, Ai XC, Zhang JP and Skibsted LH 2009. Comparison of flavonoids and isoflavonoids as antioxidants. J. Agric. Food Chem. 57: 3780-3785.

Ju Y, Tang CH, Zhao N, Zhou YW, Zhang Y, Ma L and Chen LL 2015. Application of ultrasound in food processing in the future. J. Chongqing Tech. \& Business Univ. (Nat. Sci. Ed.). 32(12): 71-74.

Li SH, Wu XJ, Zeng JY, Zhang J and Liu F 2014. Antihyperglycemic effect of Total flavonoids from Potentilla kleiniana Wight et Arn. in vitro and in vivo. Food Sci. 35(11): 246-250.

Li XC, Lin J, Gao YX, Han WJ and Chen DF 2012. Antioxidant activity and mechanism of rhizoma cimicifugae. Chem. Cebtral J. 6: 140-146.

Li YC, Ji H, Li XH, Zhang HX and Li HT 2017. Isolation of nematicidal constituents from essential oil of Kaempferia galanga L. rhizome and their activity against Heterodera avenae Wollenweber. Tropical J. Pharm. Res. 16: 59-65.

Mottaghipisheh J, Hazeri N, Valizadeh J, Maghsoodlou MT and Arjomandi R 2015. Constituents of the essential oil and antioxidant activity of extracts of Achillea eriophora from Iran. J. Essential Oil Bearing Plants. 18(1): 52-56.

Ridtitid W, Saewong C, Reanmongkol W and Wongnawa M 2008. Antinociceptic activity of the methanolic extract of Kaempferia galanga Linn. in experimental animals. J. Ethanopharm. 118(2): 225-230.

Shao CB, Wu SW and Li RB 2005. Extraction process for the total flavones of Lysimachi congestifloa Hemsl. J. Chongqing Tech. \& Business Univ. (Nat. Sci. Ed.), 22(6): 556-559.

Sun XJ, Li XX, Feng YB and Zhang LH 2015. Optimization of extracting technique assisted by ultrahigh pressure extraction (UHPE) of flavonoids from hawthorn. Sci. \& Technol. Food Industry. 36(2): 291295.

Szabo MR, Idiţoiu C, Chambre D and Lupea AX 2007. Improved DPPH determination for antioxidant activity spectrophotometric assay. Chem. Papers. 61(3): 214-216.

Wang LZ, Yang B, Du XQ and Yi C 2008. Optimisation of supercritical fluid extraction of flavonoids from Pueraria lobata. Food Chem. 108: 737-741. 
Xiang ZB and Wu XL 2017. Ultrasonic-microwave assisted extraction of total flavonoid from Scutellaria baicalensis using response surface methodology, pharm. Chem. J. 51: 318-323.

Xiang ZB, Wu XL and Zhong X 2018. Study on ultrasonic extraction techniques of total flavonoids from the leaves of Canarium album by response surface methodology. Sci. Technol. Food Industry 39(10): 211-215.

Yang L, Cao, YL, Jiang, JG, Lin QS, Chen J and Zhu L 2010. Response surface optimization of ultrasoundassisted flavonoids extraction from the flower of Citrus aurantium L. var. amara Engl. J. Separ. Sci. 33: $1349-1355$.

Zhang JF, Sun YK, Zou XL and Liu XB 2012. Optimization of the extraction technology of flavonoids from Chrysanthemum coronarium L. by microwave method. Medi. Plant. 3(2): 61-64.

(Manuscript received on 22 October, 2018; revised on 26 November, 2019) 